\title{
Driving-pressure-independent protective effects of open lung approach against experimental acute respiratory distress syndrome
}

\author{
Kentaro Tojo ${ }^{1 *}$ (D), Tasuku Yoshida ${ }^{1}$, Takuya Yazawa ${ }^{2}$ and Takahisa Goto ${ }^{1}$
}

\begin{abstract}
Background: The open lung approach (OLA) reportedly has lung-protective effects against acute respiratory distress syndrome (ARDS). Recently, lowering of the driving pressure $(\Delta P)$, rather than improvement in lung aeration per se, has come to be considered as the primary lung-protective mechanism of OLA. However, the driving pressure-independent protective effects of OLA have never been evaluated in experimental studies. We here evaluated whether OLA shows protective effects against experimental ARDS even when the $\triangle \mathrm{P}$ is not lowered.

Methods: Lipopolysaccharide was intratracheally administered to rats to establish experimental ARDS. After $24 \mathrm{~h}$, rats were mechanically ventilated and randomly allocated to the OLA or control group. In the OLA group, $5 \mathrm{cmH}_{2} \mathrm{O}$ positive end-expiratory pressure (PEEP) and recruitment maneuver (RM) were applied. Neither PEEP nor RM was applied to the rats in the control group. Dynamic $\Delta \mathrm{P}$ was kept at $15 \mathrm{cmH}_{2} \mathrm{O}$ in both groups. After $6 \mathrm{~h}$ of mechanical ventilation, rats in both groups received RM to inflate reversible atelectasis of the lungs. Arterial blood gas analysis, lung computed tomography, histological evaluation, and comprehensive biochemical analysis were performed.

Results: OLA significantly improved lung aeration, arterial oxygenation, and gas exchange. Even after RM in both groups, the differences in these parameters between the two groups persisted, indicating that the atelectasis-induced respiratory dysfunction observed in the control group is not an easily reversible functional problem. Lung histological damage was severe in the dorsal dependent area in both groups, but was attenuated by OLA. White blood cell counts, protein concentrations, and tissue injury markers in the broncho-alveolar lavage fluid (BALF) were higher in the control than in the OLA group. Furthermore, levels of CXCL-7, a platelet-derived chemokine, were higher in the BALF from the control group, indicating that OLA protects the lungs by suppressing platelet activation.
\end{abstract}

Conclusions: OLA shows protective effects against experimental ARDS, even when the $\Delta \mathrm{P}$ is not decreased. In addition to reducing $\Delta \mathrm{P}$, maintaining lung aeration seems to be important for lung protection in ARDS.

Keywords: Acute respiratory distress syndrome, Atelectasis, Driving pressure, Mechanical ventilation, Open lung approach, Platelet-derived chemokine, Positive end-expiratory pressure, Recruitment maneuver

\footnotetext{
* Correspondence: ktojo-cib@umin.net

1 Department of Anesthesiology and Critical Care Medicine, Yokohama City

University Graduate School of Medicine, Yokohama, Kanagawa, Japan

Full list of author information is available at the end of the article
}

(c) The Author(s). 2018 Open Access This article is distributed under the terms of the Creative Commons Attribution 4.0 International License (http://creativecommons.org/licenses/by/4.0/), which permits unrestricted use, distribution, and reproduction in any medium, provided you give appropriate credit to the original author(s) and the source, provide a link to the Creative Commons license, and indicate if changes were made. The Creative Commons Public Domain Dedication waiver (http://creativecommons.org/publicdomain/zero/1.0/) applies to the data made available in this article, unless otherwise stated. 


\section{Background}

Acute respiratory distress syndrome (ARDS) is a form of severe respiratory failure [1] caused by marked lung inflammatory responses during critical illness, such as severe infection, trauma, and burn [2]. The pathological features of ARDS are alveolar barrier disruption and leakage of protein-rich fluid into the alveolar spaces, causing pulmonary edema [2] and atelectasis [3, 4]. Atelectasis in ARDS not only causes respiratory failure, but also enhances lung injury through several mechanisms. First, in the atelectatic lung region, alveolar hypoxia induces inflammation $[5,6]$, pulmonary hypertension, and right cardiac failure [7]. Second, atelectasis exposes peri-atelectatic alveoli to repetitive alveolar collapse and reopening [8], and exacerbates the peri-atelectatic mechanical ventilationinduced stress $[9,10]$. Third, development of atelectasis during mechanical ventilation increases the relative tidal volume and the (driving pressure) [11, 12], which induces overdistension of aerated lung regions. Therefore, reducing atelectasis is an important aspect in the lungprotective management of ARDS.

To reduce atelectasis, the open lung approach (OLA), including application of positive end-expiratory pressure (PEEP) and the lung recruitment maneuver (RM), has been introduced and has shown some clinical benefits [13-16]. Although several mechanisms have been speculated to underlie atelectasis-induced exacerbation of lung injury as described above, the reduction in $\Delta \mathrm{P}$ has recently come to be considered as the primary lung-protective mechanism of OLA [17]. For example, some studies have indicated that the protective effects of OLA are mediated almost solely through decreases in $\Delta \mathrm{P}[18,19]$, suggesting that the primary goal in mechanically ventilated patients is lowering the $\Delta \mathrm{P}$, rather than improving lung aeration. However, it is unclear whether OLA has protective effects independent of lowered $\Delta \mathrm{P}$, because, in the previous experimental studies demonstrating the lung protective effects of OLA $[8,20-26]$, the same tidal volume was maintained in OLA-managed subjects as in control subjects. Consequently, $\Delta \mathrm{P}$ in the OLA group was lower than that in the controls in these studies, because the relative tidal volume to aerated lung volume was lowered by OLA. We hypothesized that lowering $\Delta \mathrm{P}$ alone would not be sufficient for lung-protective management and that aeration improvement would have protective effects when the $\Delta \mathrm{P}$ is not lowered. Elucidating whether OLA has effects independent of $\Delta \mathrm{P}$ can clarify the importance of lung aeration per se in the management of ARDS.

The aim of the present study was thus to elucidate whether OLA has protective effects against experimental ARDS in a rat model, compared to management without OLA, even when a similar $\Delta \mathrm{P}$ was applied in both groups.

\section{Methods}

\section{Animal experiments}

All animal experimental protocols were reviewed and approved by the Animal Research Committee of Yokohama City University. Male Sprague-Dawley rats, aged 8-9 weeks, were used for all the experiments. The animals were housed under a 12-h light/dark cycle with food and water available ad libitum.

Rats were anesthetized with intraperitoneal injection of ketamine (50 mg/kg/body weight) and xylazine ( $5 \mathrm{mg} / \mathrm{kg} /$ body weight). Under general anesthesia, the trachea was exposed through a small incision at the anterior neck and $300 \mu \mathrm{L}$ of lipopolysaccharide (LPS, Escherichia coli O111:B4, Sigma-Aldrich. St Louis, MO, USA) solution in phosphate-buffered saline (PBS) $(5 \mathrm{mg} / \mathrm{mL})$ was intratracheally administered through a 30-gauge needle. Rats were held in a $45^{\circ}$ head-up position for $1 \mathrm{~min}$ after this instillation; thereafter, oxygen was administered for $30 \mathrm{~min}$ at a flow rate of $0.5 \mathrm{~L} / \mathrm{min}$. After recovery from anesthesia, rats were returned to their cages.

At $24 \mathrm{~h}$ after LPS administration, rats were again anesthetized with intraperitoneal ketamine and xylazine injection. The left femoral vein was cannulated and a 1:1 mixture of $1 \%$ propofol and acetate Ringer solution was injected at a rate of $1 \mathrm{~mL} / \mathrm{h}$. The right carotid artery was cannulated, and arterial blood pressure was monitored. From the arterial line, heparinized normal saline was injected at $3 \mathrm{~mL} / \mathrm{h}$. Thereafter, the trachea was cannulated and connected to a mechanical ventilator (SN480-7, Shinano Seisakusho, Tokyo, Japan), which is designed for small animals. Rats were ventilated using the following parameters: fraction of inspired oxygen $\left(\mathrm{F}_{\mathrm{I}} \mathrm{O}_{2}\right), 0.4$; tidal volume, $10 \mathrm{~mL} / \mathrm{kg}$; frequency, $65 / \mathrm{min}$; and PEEP, $5 \mathrm{cmH}_{2} \mathrm{O}$. After starting mechanical ventilation, $0.4 \mathrm{mg}$ of pancuronium bromide, followed by another $0.2 \mathrm{mg}$ every $30 \mathrm{~min}$, was administered to stop spontaneous breathing. Thereafter, the recruitment maneuver (RM) was performed, with $30 \mathrm{cmH}_{2} \mathrm{O}$ for $10 \mathrm{~s}$, three times. The Y-piece of the breathing circuit was connected to the pressure transducer (Becton Dickinson, Franklin Lankes, NJ, USA) by an air-filled pressureresistant tube, and the airway pressure was recorded using a medical bedside monitor (BSM-8500, Nihon Kohden, Tokyo, Japan).

First, we recorded the inspiratory flow pattern of the small animal mechanical ventilator. Because the inspiratory flow from the ventilator is proportional to piston speed, we obtained videos of the piston movement with a digital video camera and analyzed the piston speed using ImageJ software. We confirmed that the inspiratory flow of the ventilator at end-inspiration was near zero (Fig. 1a). We therefore assumed that the peak inspiratory pressure was almost equal to the peak alveolar pressure (plateau pressure) and calculated the "dynamic" 

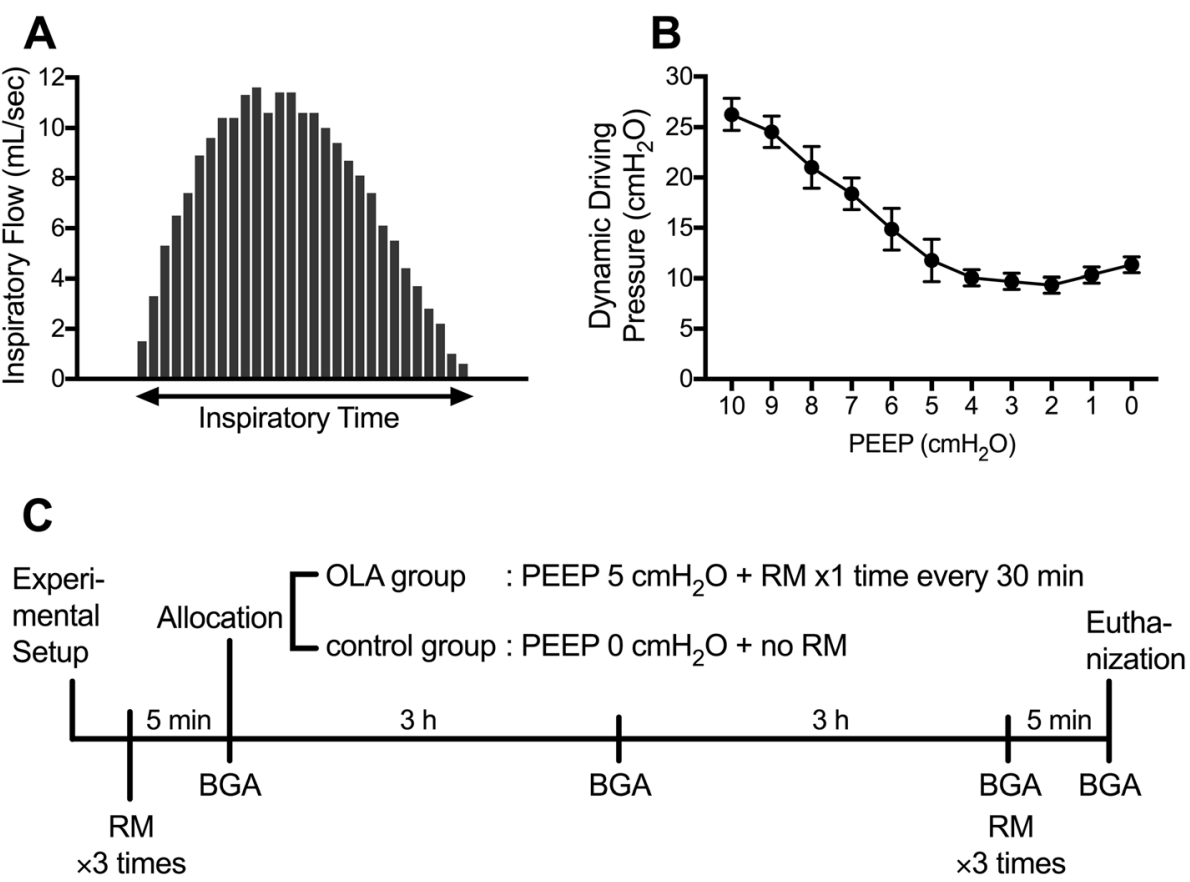

Fig. 1 Inspiratory flow pattern, dynamic driving pressures during positive end-expiratory pressure (PEEP) titration, and the experimental scheme. a Inspiratory flow pattern of the small animal ventilator ( $\mathrm{SN}-480-7$, Shinano Seisakusho). b Changes in the dynamic driving pressures when decreasing PEEP from 10 to $0 \mathrm{~cm} \mathrm{H}_{2} \mathrm{O}$ at intervals of $2 \mathrm{~cm} \mathrm{H}_{2} \mathrm{O}$. Data represent the means $\pm \mathrm{SD}$. $\mathbf{c}$ Schematic diagram of the experimental design. BGA, blood gas analysis; OLA, open lung approach; RM, recruitment maneuver

$\Delta \mathrm{P}$ as the difference between the peak inspiratory pressure and PEEP.

Subsequently, we evaluated the association between dynamic $\triangle \mathrm{P}$ and PEEP levels in rats administered with LPS $(n=3)$. After the RM, the dynamic $\Delta \mathrm{P}$ was recorded while decreasing PEEP from 10 to $0 \mathrm{cmH}_{2} \mathrm{O}$ at an interval of $2 \mathrm{cmH}_{2} \mathrm{O}$ (Fig. 1b). Based on this observation, we set the PEEP levels in the animals managed with OLA at $5 \mathrm{cmH}_{2} \mathrm{O}$, which was derived by adding $2 \mathrm{cmH}_{2} \mathrm{O}$ to the PEEP level that achieved the minimal dynamic $\triangle \mathrm{P}$.

In the main experiment (Fig. 1c), baseline physiological parameters were measured and arterial blood gas was analyzed $5 \mathrm{~min}$ after the RM. Thereafter, rats were randomly allocated to two experimental groups: the OLA and control groups. Twenty-two rats were used in the main experiment. One rat died before the experimental allocation. After the allocation, a rat in the control group died due to airway obstruction, and thus data from 20 animals were included in the final analysis $(n=10$ per group). In the OLA group, $5 \mathrm{cmH}_{2} \mathrm{O}$ PEEP was applied and the RM was performed every $30 \mathrm{~min}$. Neither PEEP nor RM was applied to rats in the control group. The tidal volume was adjusted to maintain a dynamic $\Delta \mathrm{P}$ of $15 \mathrm{cmH}_{2} \mathrm{O}$. In parallel, ventilation frequency was adjusted to maintain a constant minute volume.

After $6 \mathrm{~h}$ of mechanical ventilation, the RM was performed three times in both groups to inflate the reversible atelectatic lung region, because formation of atelectasis can often be misinterpreted as ventilatorinduced-lung injury in rats [27]. After the final RM, the setting of the mechanical ventilation for both groups was changed to the initial setting as follows: tidal volume, $10 \mathrm{~mL} / \mathrm{kg}$; frequency, 65/min; and PEEP $5 \mathrm{cmH}_{2} \mathrm{O}$. At $5 \mathrm{~min}$ after the final RM, rats were euthanized by blood removal from the right carotid artery.

Arterial blood gas analysis was performed at the 3-h time point, and pre RM and 5 min post final RM. Broncho-alveolar lavage flood (BALF) was collected by lavaging the right lung with two separate $0.5-\mathrm{ml}$ aliquots of PBS containing $0.6 \mathrm{mM}$ EDTA. The left lung was fixed in paraformaldehyde and embedded in paraffin, as described previously [5], for histological analysis.

In another series of experiments, we measured esophageal pressures during mechanical ventilation. At the cervical incision for tracheostomy, the esophagus was identified and cannulated with a 20-gauge catheter filled with normal saline [28]. Then, the cannula was connected to a pressure transducer and esophageal pressures were recorded every hour. We performed an occlusion test to confirm that the cannula was located in the appropriate position [29]. In this experiment, 10 rats were randomly allocated to the OLA and control groups ( $n=5$ per group). Transpulmonary pressures (airway pressure - esophageal pressure) at end-expiration and end-inspiration and 
transpulmonary driving pressures (end-inspiratory transpulmonary pressure - end-expiratory transpulmonary pressure) were calculated.

\section{Analysis of BALF}

Collected BALF was stained with Samson's reagent solution (Nacalai Tesque, Kyoto, Japan). White blood cells in the BALF were counted using a cell counter plate. Thereafter, BALF was centrifuged at $1000 \mathrm{~g}$ for $10 \mathrm{~min}$ at $4{ }^{\circ} \mathrm{C}$ and aliquots of the supernatant were stored at $-80{ }^{\circ} \mathrm{C}$ for quantification of total protein and cytokines. Total protein concentration in the BALF was quantified by a bicinchoninic acid (BCA) method (Thermo Fisher Scientific, Waltham, MA, USA). Multiple cytokines and tissue injury markers in the BALF were analyzed using cytokine array assays (RayBiotech, Atlanta, GA, USA) following the manufacturer's instruction. Then, proteins with significantly different levels between the two groups were quantified using the following ELISA kits according to the manufacturer's instruction: ICAM-1: DY583 (R\&D Systems, Minneapolis, MN, USA); RAGE: DY1616 (R\&D Systems); CXCL-7: ERPPBP (Thermo Fisher Scientific).

\section{Histological examinations}

The paraffin-embedded left lung sections were stained with hematoxylin and eosin as described previously [5]. Twelve fields were randomly selected from each of the dorsal or ventral lung areas (a total of 24 fields per animal), and were histopathologically evaluated in a blinded manner, following previously described methods [30].

\section{Computed tomography (CT)}

A separate group of rats $(n=4$ per group and time course) was used for CT evaluations. Either at the 3-h time point or 5 min after the final RM, rats were euthanized, and their tracheas were ligated at end-expiration. Immediately after euthanasia, a pulmonary CT image was obtained using a micro-CT imager (RIGAKU, Tokyo, Japan). The aerated lung volume was analyzed and calculated using Image software.

\section{Statistical analysis}

Data are presented as means \pm standard deviations (SD). GraphPad Prism 6 (GraphPad Software, La Jolla, CA, USA) was used for all statistical analyses. Statistical significance was set at $p<0.05$. Physiological parameters and lung histology scores were analyzed by two-way repeated-measures analysis of variance. Aerated lung volumes were analyzed by two-way analysis of variance. Post-hoc Sidak's multiple comparison test was performed when there was a significant interaction effect. Cytokine array assay data were analyzed by multiple $t$ test, using the false discovery rate approach with the two-stage step-up method of Benjamini, Krieger, and Yekutieli [31]. The false discovery rate was set at 5\%. Protein concentrations, white blood cell counts, and ELISA data were analyzed by Welch's $t$ test.

\section{Results}

Physiological and mechanical ventilation parameters

The mean arterial pressure (Fig. 2a) was lower in the OLA group at the 1-h and 2-h time-points of the experimental protocol than in the control group. However, mean arterial pressure was kept at over $70 \mathrm{mmHg}$ in all the animals. There was no significant difference in mean arterial pressure between the two groups at time points after $3 \mathrm{~h}$.

In both groups, the dynamic $\Delta \mathrm{P}$ (Fig. 2b) was maintained at $15 \mathrm{cmH}_{2} \mathrm{O}$ throughout the experimental protocol until the final RM. Both end-expiratory and end-inspiratory transpulmonary pressures were higher in the OLA group than in the control group, and transpulmonary driving pressures were kept at almost the same level between the two groups until the final RM (Additional file 1: Figure S1). Tidal volume (Fig. 2c) was significantly lower in the control group than in the OLA group, to maintain a constant dynamic $\Delta \mathrm{P}$. In parallel, the respiratory rate (Fig. 2d) was higher in the control group, to maintain the same minute ventilation volume. After the final RM, the tidal volume was set to the same value in both groups; dynamic $\Delta \mathrm{P}$ was higher in the control group $\left(20.9 \pm 1.7\right.$ vs. $\left.11.8 \pm 1.1 \mathrm{cmH}_{2} \mathrm{O}, p<0.0001\right)$. Moreover, the end-inspiratory transpulmonary pressure (Additional file 1: Figure $\mathrm{S} 1 \mathrm{~A}$ ) and transpulmonary $\Delta \mathrm{P}$ (Additional file 1: Figure S1B) were significantly higher in the control group after the final RM (transpulmonary $\Delta \mathrm{P}: 17.3 \pm 3.3$ vs. $\left.9.7 \pm 1.8 \mathrm{cmH}_{2} \mathrm{O}, p<0.0001\right)$. These results indicated that the lung compliance was lower in the control group, even after inflating the reversible atelectatic region.

The initial partial arterial pressure of oxygen $\left(\mathrm{P}_{\mathrm{a}} \mathrm{O}_{2}\right)$ (Fig. 2e) and partial arterial pressure of carbon dioxide $\left(\mathrm{P}_{\mathrm{a}} \mathrm{CO}_{2}\right)$ (Fig. 2f) values were not significantly different between the two groups. During the ventilation protocol, $\mathrm{P}_{\mathrm{a}} \mathrm{O}_{2}$ was higher and $\mathrm{P}_{\mathrm{a}} \mathrm{CO}_{2}$ was lower in the OLA group than in the control group, and the difference remained significant even after the final $\mathrm{RM}\left(\mathrm{P}_{\mathrm{a}} \mathrm{O}_{2}, 92.8\right.$ \pm 19.9 vs. $147.5 \pm 34.9 \mathrm{mmHg}, p=0.0001, \mathrm{P}_{\mathrm{a}} \mathrm{CO}_{2}, 60.6 \pm$ 7.6 vs. $35.3 \pm 3.8 \mathrm{mmHg}, p<0.0001)$.

\section{Lung CT}

At the 3-h time point of the experimental protocol and 5 min after the final RM, lung CT images were obtained at end-expiration. At the 3-h time point, atelectasis was observed particularly in the dorsal lung regions of the control group (Fig. 3a). At the same time, the measured volume of the aerated lung regions at end-expiration 


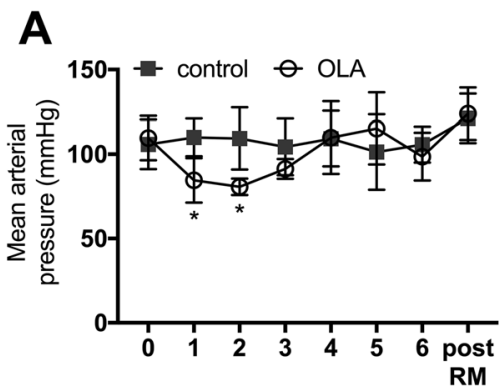

Mechanical Ventilation Time (hour)

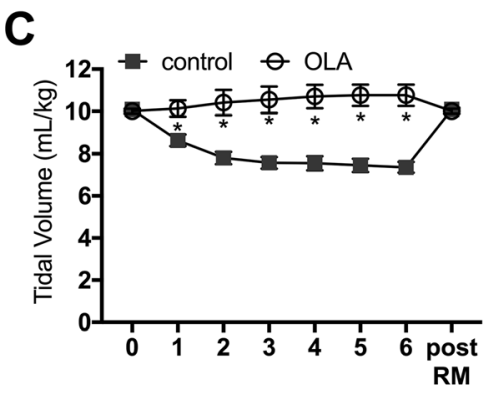

Mechanical Ventilation Time (hour)

E

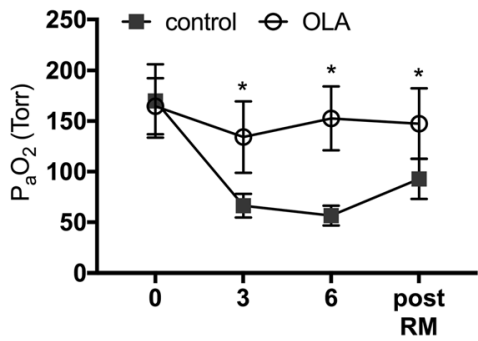

Mechanical Ventilation Time (hour)

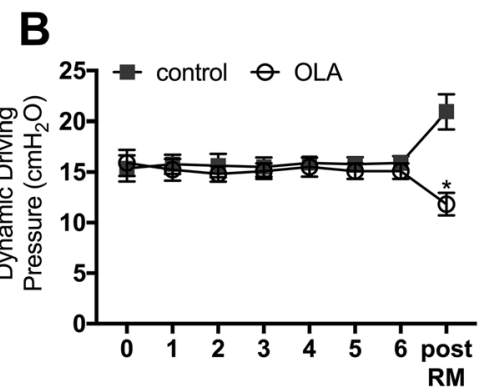

Mechanical Ventilation Time (hour)

D

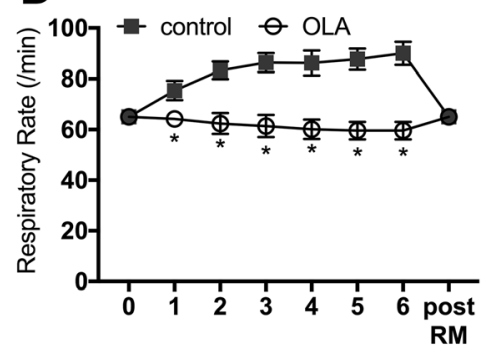

Mechanical Ventilation Time (hour)

$\mathbf{F}$

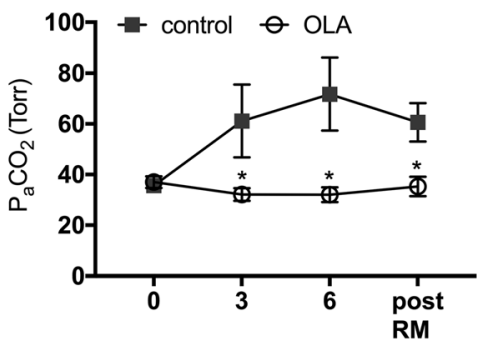

Mechanical Ventilation Time (hour)

Fig. 2 Physiological and mechanical ventilation parameters. a Mean arterial blood pressure. b Dynamic driving pressure. c Tidal volume. d Respiratory rate. e Partial pressure of arterial oxygen $\left(\mathrm{P}_{\mathrm{a}} \mathrm{O}_{2}\right)$. $\mathbf{f}$ Partial pressure of arterial carbon dioxide $\left(\mathrm{P}_{\mathrm{a}} \mathrm{CO}_{2}\right)$. ${ }^{*} p<0.05$ vs. control group. Data represent the means $\pm \mathrm{SD}$. OLA, open lung approach; $\mathrm{RM}$, recruitment maneuver

was significantly larger in the OLA group than in the control group $\left(1.63 \pm 1.08\right.$ vs. $6.83 \pm 0.75 \mathrm{~cm}^{3}, p<$ 0.0001) (Fig. 3c). After the final RM, atelectasis was reduced in the control group (Fig. 3b); however, the difference in the aerated lung volume between the OLA and control groups remained statistically significant (3.52 \pm 0.80 vs. $5.40 \pm 1.34 \mathrm{~cm}^{3}, p=0.0451$ ) (Fig. 3c).

\section{Histological lung damage}

We next evaluated the histological lung damage in the ventral (independent) and dorsal (dependent) lung areas (Fig. 4). Lung histology scores were significantly higher in the dorsal dependent area than in the ventral area, and OLA attenuated the histological damage (effect of lung area, $F=85.63, p<0.0001$; effect of OLA management, $F=5.362, p=0.0326$; interaction effect, $F=3.908$, $p=0.0636)$.
Analysis of alveolar barrier injury and inflammatory mediators

In the OLA group, the number of white blood cells in the BALF was significantly lower than in the control group $\left(354.9 \pm 124.4\right.$ vs. $207.1 \pm 84.3 \times 10^{4}$ cells/ $\mathrm{mL}, p=0.0068$ ) (Fig. 5a). Moreover, management with OLA significantly decreased the protein concentrations in BALF, which is an indicator of alveolar barrier disruption $(1292.1 \pm 438.0$ vs. $796.7 \pm 165.3 \mu \mathrm{g} / \mathrm{mL}$, $p=0.0061$ ) (Fig. 5b).

Next, we performed comprehensive analysis of inflammatory and tissue injury markers in BALF using cytokine array analysis (Fig. 5c). The concentration of CXCL7, a platelet-derived chemokine, was significantly lower in the OLA group than in the control group. Moreover, OLA decreased levels of RAGE and ICAM-1, indicators of alveolar epithelial and endothelial injury $[32,33]$, in BALF. We also confirmed that OLA 

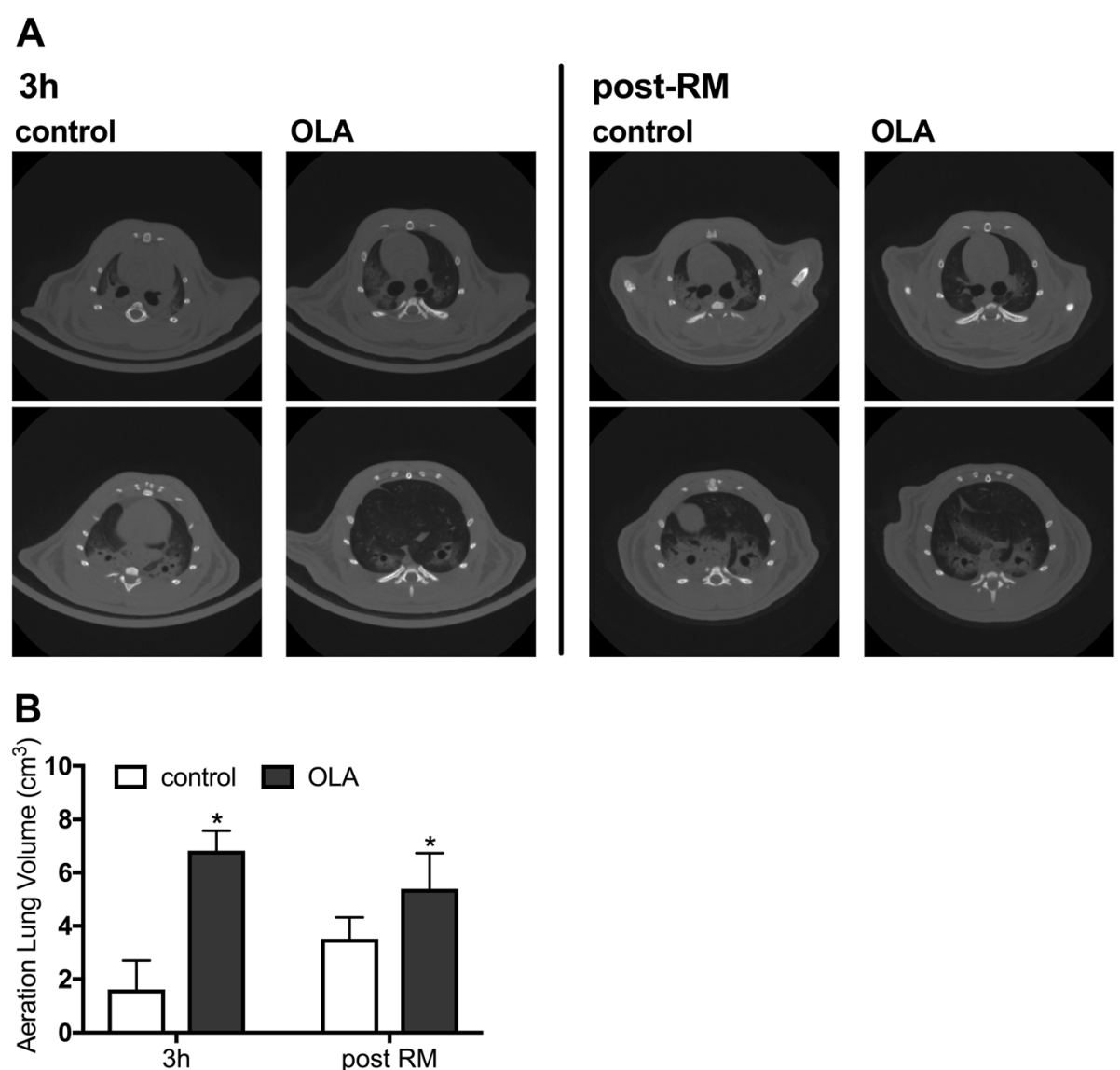

Fig. 3 Computed tomography. a Representative pulmonary computed tomography images taken after $3 \mathrm{~h}$ of mechanical ventilation or after the final recruitment maneuver following $6 \mathrm{~h}$ of mechanical ventilation. b Aerated lung volumes calculated from computed tomography images. ${ }^{*} p$ $<0.05$ vs. control group. Data represent the means \pm SD. OLA, open lung approach; RM, recruitment maneuver

decreased CXCL-7 (13,809 \pm 9322 vs. $1969 \pm 2682$ pg/ $\mathrm{mL}, p=0.0029)$, RAGE $(113,156 \pm 28,580$ vs. $44,048 \pm$ $15,904 \mathrm{pg} / \mathrm{mL}, p<0.0001)$, and ICAM-1 $(83,995 \pm 30,062$ vs. $33,912 \pm 11,796 \mathrm{pg} / \mathrm{mL}, p=0.0004$ ) levels in BALF, using ELISA (Fig. $5 \mathrm{~d}-\mathrm{f}$ ). These results indicated that OLA protects the alveolar barrier by suppressing platelet activation and neutrophil infiltration into the alveoli.

\section{Discussion}

In the present study, we demonstrated that OLA during mechanical ventilation has lung-protective effects against LPS-induced experimental ARDS, even when the dynamic $\Delta \mathrm{P}$ was not decreased. In the previous experimental studies demonstrating the benefits of OLA, such as those using PEEP, a similar tidal volume was used irrespective of whether the animals received OLA [8, 2026]. Therefore, it has remained unclear whether the protective effects are mediated by decreases in $\Delta \mathrm{P}$ or by improvement in lung aeration per se. In the present study, to maintain a similar $\Delta \mathrm{P}$ in both groups, the tidal volume was adjusted, and a significantly lower tidal volume was applied in the control group. Our results clearly demonstrated the driving pressure-independent benefits of OLA, which, to our knowledge, have not been reported previously.

Recently, Amato et al. have reported that $\Delta \mathrm{P}$ is the ventilation variable that is most strongly associated with mortality in patients with ARDS [18]. Using mediation analysis, their report demonstrated that the application of PEEP seems to be beneficial only when the $\triangle \mathrm{P}$ is lowered by the application of PEEP. Additionally, an experimental study utilizing a ventilator-induced lung injury model demonstrated that PEEP is protective only if associated with a reduced $\Delta \mathrm{P}$ [19]. The results of these reports suggest that lung protection can be achieved by lowering $\Delta \mathrm{P}$, even without improvement of lung aeration. However, it is known that development of atelectasis per se enhances alveolar stress in the periatelectatic region $[9,10]$, and causes hypoxia-induced inflammation $[5,6]$ and pulmonary circulatory failure [7]. Our present results indicate that, in addition to lowering $\Delta \mathrm{P}$, maintaining lung aeration is important for lung protective management in ARDS. 

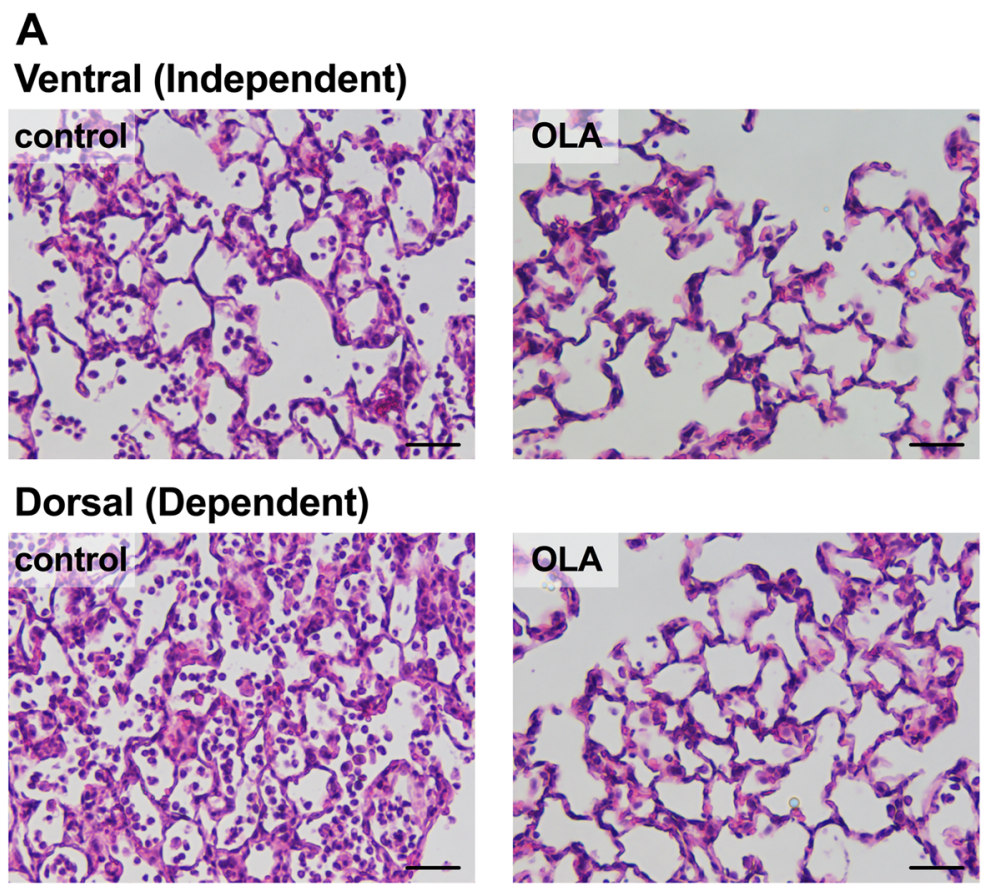

B

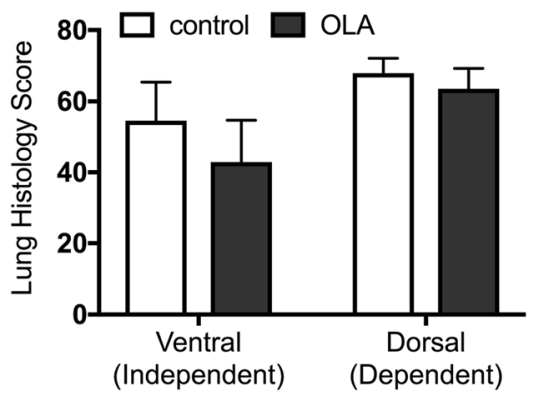

Fig. 4 Histology. a Representative images of lung sections stained with hematoxylin and eosin. b Histological scores assessed in a blinded manner. Data represent the means $\pm \mathrm{SD}$. OLA, open lung approach

In the present study, we applied both PEEP and RM as OLA. There are several methods to determine optimal PEEP during mechanical ventilation [34, 35]. We determined the PEEP level in the OLA group based on the lung mechanics required to maximize lung dynamic compliance [36]. Although there is no clear consensus as to the best approach for determining PEEP, the approach used in the present study is reported to exert lung protection with minimal adverse effects [37]. On the other hand, there are several conflicting experimental studies on RM [26, 38-41]; however, meta-analysis of clinical studies has indicated that RM in patients with ARDS may reduce intensive care unit mortality $[14,15]$. Therefore, we believe there is some rationale for utilizing RMs as a part of OLA. Future studies should investigate the individual effects of RM and PEEP.

As expected, lung aeration, arterial oxygenation, and gas exchange were significantly better in the rats receiving OLA than in rats managed without OLA during the mechanical ventilation protocol. We finally performed the RM to ensure that we did not misinterpret the formation of atelectasis as lung damage [27]. In fact, in the control group, RM after $6 \mathrm{~h}$ of mechanical ventilation increased the aerated lung volume and improved arterial oxygenation, and decreased carbon dioxide levels; however, there were significant differences in these parameters between the OLA and control groups even after the RM. These results indicate that atelectasis not only causes oxygenation impairment, but also induces respiratory dysfunction that could not be easily reversed by RM.

Lung histologic analysis and analysis of BALF revealed that OLA attenuated neutrophil infiltration and alveolar barrier protein leakage. Moreover, levels of the alveolar epithelial and endothelial injury markers, RAGE and 


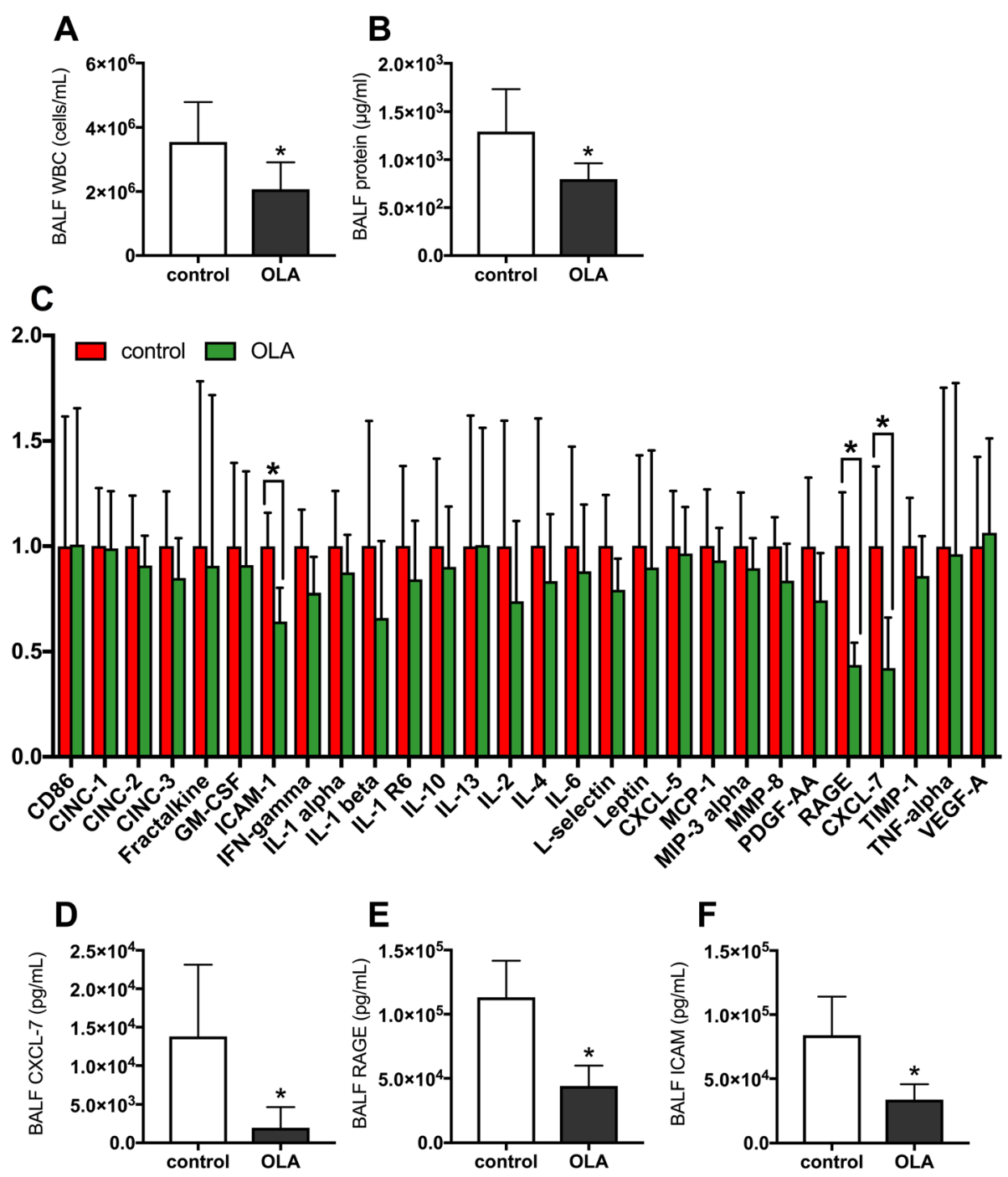

Fig. 5 Analysis of bronchoalveolar lavage fluids (BALF). a White blood cell counts (WBC). b Protein concentrations. c Comprehensive analysis of inflammatory and tissue injury markers using cytokine array analysis. $\mathbf{d}$ Intercellular adhesion molecule-1 (ICAM-1), e soluble receptor for advanced glycation end products (RAGE), $\mathbf{f}$ CXC chemokine ligand-1 (CXCL-7) concentrations in the BALF quantified by ELISA. * $p<0.05$ vs. control group. Data represent the means $\pm S D$. OLA, open lung approach

ICAM-1 [32, 33], in the BALF were significantly lower in the OLA group than in the control group. These findings also indicate that the atelectasis-induced respiratory dysfunction observed in the control group is not only an easily reversible functional problem, but is also accompanied by tissue injury. Although the observation period in the present study was only $6 \mathrm{~h}$, our results show the suppression of alveolar tissue injury by OLA. Therefore, it is plausible that OLA would yield long-term clinical benefits, such as prolongation of ventilator-free days or improvement of mortality.

The comprehensive analysis of inflammatory cytokines revealed that OLA decreased the level of CXCL-7, a platelet-derived chemokine in the BALF. Hypoxia is a known cause of platelet activation [42]. Therefore, OLA might attenuate platelet activation by decreasing hypoxic atelectatic lung regions. Recently, the potential contribution of CXCL-7 to acute lung injury has been reported in a study using knock-out mice [43]. It is possible that suppression of CXCL-7 by OLA leads to decreased neutrophil infiltration into the alveolar space. Moreover, platelet activation might enhance pulmonary vascular thrombosis, which may in turn increase the dead space fraction, with $\mathrm{CO}_{2}$ retention, in the control group. As platelet activation and the increase in the platelet-derived CXCL-7 may be a potential therapeutic target for atelectasis-induced lung injury, further studies are warranted.

The arterial carbon dioxide level was significantly higher in the control group throughout the ventilation 
protocol. One of the possible reasons for $\mathrm{CO}_{2}$ retention was the increase in the relative dead space fraction due to the smaller tidal volume in the control group than in the OLA group. Another explanation is that alveolar hypoxia in the control group might have disturbed pulmonary blood flow and gas exchange through hypoxia-induced pulmonary vasoconstriction. Moreover, as mentioned above, hypoxia-induced platelet activation might also have disturbed the pulmonary circulation through thrombosis formation. Hypercapnia is known to exert anti-inflammatory effects [44-46] by suppressing NF-кB $[47,48]$. Therefore, it is unlikely that the hypercapnia observed in the control group worsened the inflammation and tissue injury. On the other hand, hypercapnia has been reported as an unfavorable prognostic factor in pneumonia $[49,50]$ and in mechanically ventilated patients [51], possibly due to immunosuppression [52-55]. Thus, the improvement of gas exchange achieved by OLA may have advantages in terms of appropriate immunological responses against infection, which is the leading cause of ARDS.

The clinical efficacy of OLA has been evaluated in several studies. A recent meta-analysis has revealed that the high-PEEP strategy is not associated with mortality reduction, as compared with low-PEEP management [16]. Moreover, a recent randomized controlled trial, named Alveolar Recruitment for Acute Respiratory Distress Syndrome Trial (ART) [56], demonstrated that the management of ARDS patients with lung recruitment and titrated PEEP increased all-cause mortality, as compared to the low-PEEP strategy proposed by ARDSNet [57]. One of the potential explanations for this finding is that lung recruitability was low in the patients in the ART trial and that the harmful effects of OLA, such as circulatory failure, overdistension, or barotrauma, overcame its beneficial effects. In the present study, although the mean arterial pressure was significantly lower in the OLA group for the first $2 \mathrm{~h}$ of the ventilation protocol, lung aeration was significantly improved in the OLA group and no barotrauma was observed. The high lung-recruitability in the present study might have favorably influenced the effects of OLA. Additionally, the control group in the ART trial received substantial PEEP, whereas the control group in the present study was managed with zero PEEP. Although the present study suggests that lung aeration should be maintained to protect lungs against ARDS-related damage, it is also necessary to balance the beneficial and harmful effects of OLA. How to optimize OLA is a very important future focus for research in the mechanical ventilation of patients with ARDS.

The present study had some limitations. First, we applied only one level of $\Delta \mathrm{P}$ to animals. We chose 15
$\mathrm{cmH}_{2} \mathrm{O}$ as the level of $\Delta \mathrm{P}$, because it seemed to be the upper limit of the safe $\Delta \mathrm{P}$ level in patients with ARDS $[17,58]$, while a $\Delta \mathrm{P}$ of less than $15 \mathrm{cmH}_{2} \mathrm{O}$ could cause severe hypoxia and hypercapnia in the control group. However, it is unclear whether the protective effects of OLA would be observed when using a different level of $\Delta \mathrm{P}$. Second, we used only one animal model of ARDS, intratracheal LPS-induced ARDS, in the present study. In an ARDS model with a different etiology, such as systemic sepsis, the effects of OLA might be different. Third, management with zero PEEP in the control group is far from standard clinical practice. We used zero PEEP management as the control to recapitulate development of the marked atelectasis observed in patients with ARDS. However, this may limit the generalization of our results to clinical settings.

\section{Conclusions}

In conclusion, OLA improved lung aeration and had protective effects against experimental ARDS, independent of $\Delta \mathrm{P}$. In addition to lowering $\Delta \mathrm{P}$, maintaining lung aeration is an important aspect of lung protective management in ARDS.

\section{Additional file}

Additional file 1: Figure S1. Transpulmonary pressures. The data were obtained from a separate group of animals, different to those used in the main experiment. (A) End-inspiratory transpulmonary pressure. (B) Endexpiratory transpulmonary pressure. (C) Transpulmonary $\Delta P$. Transpulmonary pressures were calculated by subtracting esophageal pressures from airway pressures: ${ }^{*} p<0.05$ vs. control group. Data represent the means $\pm \mathrm{SD}$. (TIFF $850 \mathrm{~kb}$ )

\section{Abbreviations}

ARDS: Acute respiratory distress syndrome; BALF: Broncho-alveolar lavage fluid; CT: Computed tomography; CXCL-7: CXC chemokine ligand-1;

ELISA: Enzyme-linked immunosorbent assay; ICAM-1: Intercellular adhesion molecule-1; OLA: Open lung approach; $\mathrm{P}_{2} \mathrm{CO}_{2}$ : Partial arterial pressure of carbon dioxide; $\mathrm{P}_{\mathrm{a}} \mathrm{O}_{2}$ : Partial arterial pressure of oxygen; PBS: Phosphatebuffered saline; PEEP: Positive end-expiratory pressure; RAGE: Receptor for advanced glycation end products; RM: Recruitment maneuver

\section{Acknowledgements}

We thank Ms Akiko Adachi and Ms Yuki Yuba (Department of Anesthesiology and Critical Care Medicine, Yokohama City University Graduate School of Medicine) for their technical assistance. We would also like to acknowledge Dr Takahiro Mihara (YCU Center for Novel and Exploratory Clinical Trials, Yokohama City University) for his helpful advice on statistics.

\section{Funding}

This study was supported, in part, by Grants-in-Aid for Scientific Research from the Japan Society for the Promotion of Science (16 K20395, 15 K20054).

\section{Availability of data and materials}

The datasets generated and/or analyzed during the current study are available from the corresponding author upon reasonable request.

\section{Authors' contributions}

$\mathrm{KT}$ conceived and designed the study, performed experiments, and wrote the manuscript. TYoshida designed the study and revised the manuscript. 
TYazawa performed histological examinations and revised the manuscript. TG revised the manuscript. All authors approved the final manuscript.

\section{Ethics approval}

All animal experimental protocols were reviewed and approved by the Animal Research Committee of Yokohama City University.

\section{Consent for publication}

Not applicable.

\section{Competing interests}

The authors declare that they have no competing interests.

\section{Publisher's Note}

Springer Nature remains neutral with regard to jurisdictional claims in published maps and institutional affiliations.

\section{Author details}

Department of Anesthesiology and Critical Care Medicine, Yokohama City University Graduate School of Medicine, Yokohama, Kanagawa, Japan.

${ }^{2}$ Department of Pathology, Dokkyo Medical University, Tochigi, Japan.

\section{Received: 8 April 2018 Accepted: 8 August 2018}

\section{Published online: 23 September 2018}

\section{References}

1. Definition Task Force ARDS, Ranieri VM, Rubenfeld GD, Thompson BT, Ferguson ND, Caldwell E, Fan E, Camporota L, Slutsky AS. Acute respiratory distress syndrome: the Berlin definition. JAMA. 2012;307:2526-33.

2. Thompson BT, Chambers RC, Liu KD. Acute respiratory distress syndrome. $\mathrm{N}$ Engl J Med. 2017;377:562-72

3. Puybasset L, Cluzel P, Chao N, Slutsky AS, Coriat P, Rouby JJ. A computed tomography scan assessment of regional lung volume in acute lung injury. The CT scan ARDS study group. Am J Respir Crit Care Med. 1998;158:1644-55.

4. Puybasset L, Cluzel P, Gusman P, Grenier P, Preteux F, Rouby JJ. Regional distribution of gas and tissue in acute respiratory distress syndrome. I. Consequences for lung morphology. Intensive Care Med. 2000;26:857-69.

5. Tojo K, Nagamine Y, Yazawa T, Mihara T, Baba Y, Ota S, Goto T, Kurahashi K. Atelectasis causes alveolar hypoxia-induced inflammation during uneven mechanical ventilation in rats. Intensive Care Med Exp. 2015;3:18.

6. Tojo K, Goto T, Kurahashi K. Protective effects of continuous positive airway pressure on a nonventilated lung during one-lung ventilation. Eur J Anaesthesiol. 2016:33:776-83.

7. Duggan M, McCaul CL, McNamara PJ, Engelberts D, Ackerley C, Kavanagh BP. Atelectasis causes vascular leak and lethal right ventricular failure in uninjured rat lungs. Am J Respir Crit Care Med. 2003;167:1633-40.

8. Muscedere JG, Mullen JB, Gan K, Slutsky AS. Tidal ventilation at low airway pressures can augment lung injury. Am J Respir Crit Care Med. 1994;149:1327-34.

9. Mead J, Takishima T, Leith D. Stress distribution in lungs: a model of pulmonary elasticity. J Appl Physiol. 1970;28:596-608.

10. Retamal J, Bergamini B, Carvalho AR, Bozza FA, Borzone G, Borges J, Larsson A, Hedenstierna G, Bugedo G, Bruhn A. Non-lobar atelectasis generates inflammation and structural alveolar injury in the surrounding healthy tissue during mechanical ventilation. Crit Care. 2014;18:505.

11. Cinnella G, Grasso S, Raimondo P, D'Antini D, Mirabella L, Rauseo M Dambrosio M. Physiological effects of the open lung approach in patients with early, mild, diffuse acute respiratory distress syndrome: an electrical impedance tomography study. Anesthesiology. 2015:123:1113-21.

12. Kacmarek RM, Villar J, Sulemanji D, Montiel R, Ferrando C, Blanco J, Koh Y, Soler JA, Martínez D, Hernández M, Tucci M, Borges JB, Lubillo S, Santos A Araujo JB, Amato MBP, Suarez-Sipmann F. Open lung approach for the acute respiratory distress syndrome. Crit Care Med. 2016:44:32-42

13. Briel M, Meade M, Mercat A, Brower RG, Talmor D, Walter SD, Slutsky AS, Pullenayegum E, Zhou Q, Cook D, Brochard L, Richard J-CM, Lamontagne F, Bhatnagar N, Stewart TE, Guyatt G. Higher vs lower positive end-expiratory pressure in patients with acute lung injury and acute respiratory distress syndrome: systematic review and meta-analysis. JAMA. 2010;303:865-73.

14. Suzumura ÉA, Figueiró M, Normilio-Silva K, Laranjeira L, Oliveira C, Buehler AM, Bugano D, Passos Amato MB, Ribeiro Carvalho CR, Berwanger O, Cavalcanti $A B$. Effects of alveolar recruitment maneuvers on clinical outcomes in patients with acute respiratory distress syndrome: a systematic review and meta-analysis. Intensive Care Med. 2014:40:1227-40.

15. Hodgson C, Goligher EC, Young ME, Keating JL, Holland AE, Romero L, Bradley SJ, Tuxen D. Recruitment manoeuvres for adults with acute respiratory distress syndrome receiving mechanical ventilation. Cochrane Database Syst Rev. 2016;11:CD006667.

16. Walkey AJ, Del Sorbo L, Hodgson CL, Adhikari NKJ, Wunsch H, Meade MO, Uleryk E, Hess D, Talmor DS, Thompson BT, Brower RG, Fan E. Higher PEEP versus lower PEEP strategies for patients with acute respiratory distress syndrome. A systematic review and meta-analysis. Ann Am Thorac Soc. 2017:14:S297-303.

17. Bugedo G, Retamal J, Bruhn A. Driving pressure: a marker of severity, a safety limit, or a goal for mechanical ventilation? Crit Care. 2017:21:199.

18. Amato MBP, Meade MO, Slutsky AS, Brochard L, Costa ELV, Schoenfeld DA, Stewart TE, Briel M, Talmor D, Mercat A, Richard J-CM, Carvalho CRR, Brower $R G$. Driving pressure and survival in the acute respiratory distress syndrome. N Engl J Med. 2015;372:747-55.

19. Protti A, Andreis DT, Milesi M, lapichino GE, Monti M, Comini B, Pugni P, Melis V, Santini A, Dondossola D, Gatti S, Lombardi L, Votta E, Carlesso E, Gattinoni L. Lung anatomy, energy load, and ventilator-induced lung injury. Intensive Care Med Exp. 2015:3:34.

20. Webb HH, Tierney DF. Experimental pulmonary edema due to intermittent positive pressure ventilation with high inflation pressures. Protection by positive end-expiratory pressure. Am Rev Respir Dis. 1974;110:556-65.

21. Tremblay L, Valenza F, Ribeiro SP, Li J, Slutsky AS. Injurious ventilatory strategies increase cytokines and c-fos m-RNA expression in an isolated rat lung model. J Clin Invest. 1997;99:944-52.

22. Chiumello D, Pristine G, Slutsky AS. Mechanical ventilation affects local and systemic cytokines in an animal model of acute respiratory distress syndrome. Am J Respir Crit Care Med. 1999;160:109-16.

23. Schreiber T, Hueter L, Gaser E, Schmidt B, Schwarzkopf K, Rek H, Karzai W. PEEP has beneficial effects on inflammation in the injured and no deleterious effects on the noninjured lung after unilateral lung acid instillation. Intensive Care Med. 2006:32:740-9.

24. Ko SC, Zhang H, Haitsma JJ, Cheng KC, Li CF, Slutsky AS. Effects of PEEP levels following repeated recruitment maneuvers on ventilator-induced lung injury. Acta Anaesthesiol Scand. 2008;52:514-21.

25. Krebs J, Pelosi P, Tsagogiorgas C, Zoeller L, Rocco PR, Yard B, Luecke T. Open lung approach associated with high-frequency oscillatory or low tidal volume mechanical ventilation improves respiratory function and minimizes lung injury in healthy and injured rats. Crit Care. 2010;14:R183.

26. Reiss LK, Kowallik A, Uhlig S. Recurrent recruitment manoeuvres improve lung mechanics and minimize lung injury during mechanical ventilation of healthy mice. PLoS One. 2011;6:e24527.

27. Wilson MR, Patel BV, Takata M. Ventilation with "clinically relevant" high tidal volumes does not promote stretch-induced injury in the lungs of healthy mice. Crit Care Med. 2012:40:2850-7.

28. Beda A, Güldner A, Carvalho AR, Zin WA, Carvalho NC, Huhle R, GiannellaNeto A, Koch T, de Abreu MG. Liquid- and air-filled catheters without balloon as an alternative to the air-filled balloon catheter for measurement of esophageal pressure. PLoS One. 2014:9:e103057.

29. Grieco DL, Chen L, Brochard L. Transpulmonary pressure: importance and limits. Ann Transl Med. 2017:5:285.

30. Matute-Bello G, Downey G, Moore BB, Groshong SD, Matthay MA, Slutsky AS, Kuebler WM. An official American Thoracic Society workshop report: features and measurements of experimental acute lung injury in animals. Am J Respir Cell Mol Biol. 2011;44:725-38.

31. Benjamini Y, Krieger AM, Biometrika DY. Adaptive linear step-up procedures that control the false discovery rate. Biometrika. 2006;93:491-507.

32. Reinhart K, Bayer O, Brunkhorst F, Meisner M. Markers of endothelial damage in organ dysfunction and sepsis. Crit Care Med. 2002;30:S302-12.

33. Uchida T, Shirasawa M, Ware LB, Kojima K, Hata Y, Makita K, Mednick G, Matthay ZA, Matthay MA. Receptor for advanced glycation end-products is a marker of type I cell injury in acute lung injury. Am J Respir Crit Care Med. 2006;173:1008-15.

34. Gattinoni L, Carlesso E, Cressoni M. Selecting the "right" positive endexpiratory pressure level. Curr Opin Crit Care. 2015;21:50-7.

35. Nieman GF, Satalin J. Andrews P, Aiash H, Habashi NM, Gatto LA Personalizing mechanical ventilation according to physiologic parameters to stabilize alveoli and minimize ventilator induced lung injury (VILI). Intensive Care Med Exp. 2017;5:1. 
36. Suarez-Sipmann F, Böhm SH, Tusman G, Pesch T, Thamm O, Reissmann H, Reske A, Magnusson A, Hedenstierna G. Use of dynamic compliance for open lung positive end-expiratory pressure titration in an experimental study. Crit Care Med. 2007;35:214-21.

37. Carvalho ARS, Jandre FC, Pino AV, Bozza FA, Salluh J, Rodrigues R, Ascoli FO, Giannella-Neto A. Positive end-expiratory pressure at minimal respiratory elastance represents the best compromise between mechanical stress and lung aeration in oleic acid induced lung injury. Crit Care. 2007;11:R86.

38. Koh W-J, Suh GY, Han J, Lee S-H, Kang EH, Chung MP, Kim H, Kwon OJ. Recruitment maneuvers attenuate repeated derecruitment-associated lung injury. Crit Care Med. 2005;33:1070-6.

39. Santiago VR, Rzezinski AF, Nardelli LM, Silva JD, Garcia CSNB, MaronGutierrez T, Ornellas DS, Morales MM, Capelozzi VL, Marini J, Pelosi P, Rocco PRM. Recruitment maneuver in experimental acute lung injury: the role of alveolar collapse and edema. Crit Care Med. 2010;38:2207-14.

40. Engel M, Nowacki RME, Reiss LK, Uhlig S, Willems CHMP, Kloosterboer N, van Iwaarden JF, Sewing ACP, Seehase M, Lambermont VAC, Collins JJP, Zimmermann LI, Vos GD, Kramer BW. Comparison of recruitment manoeuvres in ventilated sheep with acute respiratory distress syndrome. Lung. 2012;191:77-86.

41. Ambrosio AM, Luo R, Fantoni DT, Gutierres C, Lu Q, Gu W-J, Otsuki DA, Malbouisson LMS, Auler JOC, J-J ROUBY, Experimental ARDS Study Group. Effects of positive end-expiratory pressure titration and recruitment maneuver on lung inflammation and hyperinflation in experimental acid aspiration-induced lung injury. Anesthesiology. 2012;117:1322-34.

42. Tyagi T, Ahmad S, Gupta N, Sahu A, Ahmad Y, Nair V, Chatterjee T, Bajaj N, Sengupta S, Ganju L, Singh SB, Ashraf MZ. Altered expression of platelet proteins and calpain activity mediate hypoxia-induced prothrombotic phenotype. Blood. 2014;123:1250-60.

43. Bdeir K, Gollomp K, Stasiak M, Mei J, Papiewska-Pajak I, Zhao G, Worthen GS, Cines DB, Poncz M, Kowalska MA. Platelet-specific chemokines contribute to the pathogenesis of acute lung injury. Am J Respir Cell Mol Biol. 2017;56:261-70.

44. Laffey JG, Engelberts D, Kavanagh BP. Buffering hypercapnic acidosis worsens acute lung injury. Am J Respir Crit Care Med. 2000;161:141-6.

45. Laffey JG, Honan D, Hopkins N, Hyvelin J-M, Boylan JF, McLoughlin P. Hypercapnic acidosis attenuates endotoxin-induced acute lung injury. Am J Respir Crit Care Med. 2004;169:46-56.

46. Nichol AD, O'Cronin DF, Naughton F, Hopkins N, Boylan J, McLoughlin P. Hypercapnic acidosis reduces oxidative reactions in endotoxin-induced lung injury. Anesthesiology. 2010;113:116-25.

47. Contreras M, Ansari B, Curley G, Higgins BD, Hassett P, OToole D, Laffey JG. Hypercapnic acidosis attenuates ventilation-induced lung injury by a nuclear factor-kB-dependent mechanism. Crit Care Med. 2012;40:2622-30.

48. Horie S, Ansari B, Masterson C, Devaney J, Scully M, OToole D, Laffey JG. Hypercapnic acidosis attenuates pulmonary epithelial stretch-induced injury via inhibition of the canonical NF-kB pathway. Intensive Care Med Exp. 2016;4:1.

49. Sin DD, Man SFP, Marrie TJ. Arterial carbon dioxide tension on admission as a marker of in-hospital mortality in community-acquired pneumonia. Am J Med. 2005;118:145-50.

50. Laserna E, Sibila O, Aguilar PR, Mortensen EM, Anzueto A, Blanquer JM, Sanz F, Rello J, Marcos PJ, Velez MI, Aziz N, Restrepo MI. Hypocapnia and hypercapnia are predictors for ICU admission and mortality in hospitalized patients with community-acquired pneumonia. Chest. 2012;142:1193-9.

51. Tiruvoipati R, Pilcher D, Buscher H, Botha J, Bailey M. Effects of hypercapnia and Hypercapnic acidosis on hospital mortality in mechanically ventilated patients. Crit Care Med. 2017;45:e649-56.

52. O'Croinin DF, Nichol AD, Hopkins N, Boylan J, O'Brien S, O'Connor C, Laffey $J G$, McLoughlin P. Sustained hypercapnic acidosis during pulmonary infection increases bacterial load and worsens lung injury. Crit Care Med. 2008;36:2128-35.

53. Wang N, Gates KL, Trejo H, Silvio Favoreto J, Schleimer RP, Sznajder Jl, Beitel GJ, Sporn PHS. Elevated CO2 selectively inhibits interleukin-6 and tumor necrosis factor expression and decreases phagocytosis in the macrophage. FASEB J. 2010;24:2178-90.

54. Gates KL, Howell HA, Nair A, Vohwinkel CU, Welch LC, Beitel GJ, Hauser AR Sznajder Jl, Sporn PHS. Hypercapnia impairs lung neutrophil function and increases mortality in murine Pseudomonas pneumonia. Am J Respir Cell Mol Biol. 2013;49:821-8.

55. Lu Z, Casalino-Matsuda SM, Nair A, Buchbinder A, Budinger GRS, Sporn PHS Gates KL. A role for heat shock factor 1 in hypercapnia-induced inhibition of inflammatory cytokine expression. FASEB J. 2018;32:3614-22.
56. Cavalcanti $A B$, Suzumura ÉA, Laranjeira LN, de Moraes Paisani D, Damiani LP, Guimarães HP, Romano ER, de Moraes Regenga M, LNT T, Teixeira C, de Oliveira RP, Machado FR, Diaz-Quijano FA, de Alencar Filho MS, Maia IS, Caser EB, de Oliveira Filho W, de Carvalho Borges $M$, de Aquino Martins $P$, Matsui M, Ospina-Tascón GA, Giancursi TS, Giraldo-Ramirez ND, Vieira SRR, da Graç a Pasquotto de Lima Assef M, Hasan MS, Szczeklik W, Rios F, Amato $M B P$, Berwanger $O$, et al. Effect of lung recruitment and titrated positive end-expiratory pressure (PEEP) vs low PEEP on mortality in patients with acute respiratory distress syndrome: a randomized clinical trial. JAMA. 2017; 318:1335-45.

57. Brower RG, Lanken PN, Maclntyre N, Matthay MA, Morris A, Ancukiewicz M, Schoenfeld D, Thompson BT, National Heart, Lung, and Blood Institute ARDS Clinical Trials Network. Higher versus lower positive end-expiratory pressures in patients with the acute respiratory distress syndrome. N Engl J Med. 2004:351:327-36.

58. Chiumello D, Carlesso E, Brioni M, Cressoni M. Airway driving pressure and lung stress in ARDS patients. Crit Care. 2016;20:276.

\section{Ready to submit your research? Choose BMC and benefit from:}

- fast, convenient online submission

- thorough peer review by experienced researchers in your field

- rapid publication on acceptance

- support for research data, including large and complex data types

- gold Open Access which fosters wider collaboration and increased citations

- maximum visibility for your research: over $100 \mathrm{M}$ website views per year

At $\mathrm{BMC}$, research is always in progress.

Learn more biomedcentral.com/submissions 